Chirurgia (2021) 116: 89-101

No. 1, January - February

Copyright@ Celsius

http://dx.doi.org/10.21614/chirurgia.116.1.89

\title{
A Novel Indocyanine Green Fluorescence-Guided Laparoscopic Technique to Map the Site of Obscure Gastrointestinal Haemorrhage
}

\author{
Cătălin Copăescu ${ }^{1,2^{*}}$, Clarisa Bîrlog ${ }^{1}$, Florin Turcu', Adrian Săftoiu' ${ }^{1,3}$ \\ ${ }^{1}$ Ponderas Academic Hospital Bucharest, Romania \\ 2"GT Popa" University of Medicine and Pharmacy, Iași, Romania \\ ${ }^{3}$ University of Medicine and Pharmacy Craiova, Romania
}

${ }^{*}$ Corresponding author: Catalin Copaescu, MD PhD Associated Professor of Surgery Ponderas Academic Hospital Nicolae Caramfil Street, no. 85 A district 1, Bucharest, Romania

E-mail: catalin.copaescu@ponderas-ah.ro

\section{Rezumat}

Identificarea sursei de sângerare digestivă obscură printr-o nouă tehnică laparoscopică ghidată ICG

Scopul studiului: Evaluarea fezabilității unei noi metode de localizare pe cale laparoscopică a sursei de sângerare digestivă obscură, metodă ghidată de fluorescența indocianinei (ICG) în etapa tardivă de metabolizare.

Metodă: Studiul de fezabilitate a inclus pacienți cu modificări chirurgicale ale anatomiei digestive, diagnosticați cu sângerare digestivă manifestă, fără sursă identificabilă prin metode endoscopice şi imagistice, la care controlul sângerării era urgent. Cinci ml de soluție ICG se injectează intravenos şi se efectuează inspecția laparoscopică a cavității peritoneale în etapa de washout vascular. Localizarea zonei de origine a hemoragiei este promptă şi controlul acesteia se realizează laparoscopic sau endoscopic.

Rezultate:Două cazuri au fost incluse în acest studiu începând cu 2020. Cazul 1: pacient 43 ani, cu bypass gastric pe ansă în Y, cu sângerare digestivă repetată. Semnalul fluorescent în etapa de washout a fost identificat la nivelul duodenului şi atenuat la nivelul stomacului restant. Endoscopia transgastrică asistată laparoscopic a identificat sursa de sângerare la nivelul liniei de agrafare a stomacului restant şi hemostaza s-a obținut prin suturare cu fire. Cazul 2: pacient 66 ani, cu rezecție Whipple prin abord deschis cu nouă luni anterior prezentării pentru sângerare 
digestivă repetată. La inspecția laparoscopică a ansei bilio-pancreatice s-a observat fluorescență intensă până la capătul proximal al acesteia. Endoscopia a confirmat sângerarea activă din varice jejunale ectopice de la nivelul anastomozei coledoco-jejunale. Hemostaza s-a obținut prin coagulare endoscopică cu plasma argon.

Concluzii: Sursa de sângerare digestivă obscură poate fi identificată folosind o nouă metodă de localizare prin abord laparoscopic ghidat de fluorescența ICG, permițând astfel controlul prompt al hemoragiei. Din datele noastre, cazurile raportate sunt primele în care s-a aplicat tehnica descrisă.

Cuvinte cheie: sângerare digestivă, bypass gastric, duodenopancreatectomie, verde de indocianină, laparoscopie în infraroşu

\section{Abstract}

The aim of our study was to explore the feasibility of a novel fluorescence-guided laparoscopic technique to localize the obscure GI haemorrhage, using the vascular wash-out properties of indocyanine green (ICG).

Method: The feasability study included patients with previous surgical modifications of the gut architecture, qualified as an overt obscure GI bleeding with an urgent need to be localized and controlled. Five $\mathrm{mL}$ of ICG was injected intravenously and laparoscopic infrared inspection was performed 30 minutes after the dye was eliminated from the bloodstream. The bleeding area mapping was demonstrated and the haemostasis was carefully performed using endoscopy or laparoscopic techniques.

Results:A series of two cases were included in our fesability study so far. Case 1. A 43-year old male, who recently received a Laparoscopic Roux-en-Y gastric bypass (RYGB), developed a recurrent GI bleeding. Post dye wash-out intense signal was demonstrated at the level of duodenum and weaker at the gastric remnant. The laparoscopic trans-gastric exploration of the remnant identified an active bleeding source siding the stapled line and haemostasis was achieved with laparoscopic ligation using stitches. Case 2. A 66-year old male patient who underwent an open Whipple resection nine months before, was admitted for a repeated GI bleeding. The inspection of the biliopancreatic limb noticed an intense fluorescent signal toward the enteral proximal end. Upper digestive endoscopy confirmed the presence of an active bleeding source from ectopic jejunal varices siding the choledoco-jejunal anastomosis. Argon plasma coagulation was performed endoscopically and achieved hemostasis.

Conclusions:A successful novel ICG fluorescence-guided laparoscopic mapping technique was used to localize the site of the obscure GI haemorrhage and to facilitate the prompt bleeding control. To the best of our knowledge these are the first published cases for which this technique was used.

Key words: GI bleeding, gastric bypass, pancreatoduodenectomy, indocyanine green, infrared laparoscopy

\section{Introduction}

Gastrointestinal (GI) bleeding is a potentially life-threatening medical condition, occurring as an evolutive complication of a digestive track disorder or, as a postoperative complica- tion of any surgery of the gut $(1,2)$. Despite the recent advances and the wide use of endoscopic visualization (flexible video-endoscopes or video-capsule) and the progress of radiographic imaging [tagged red blood cell scintigraphy, computed tomographic (CT) 
angiography, magnetic resonance angiography (MRA) and angiography] GI bleeding can remain obscure or inaccessible for these techniques $(3,4)$.

The obscure GI bleeding, overt or occult, is defined as a recurrent bleeding in which the source is not identified with the abovementioned investigations $(5,6)$. Facing the reality, the diagnostic work-up of an obscure GI bleeding can be inoperable due to clinical or institutional limitations (7) while, the recommended therapeutic solutions are not always easy to access. Using surgery to broaden the diagnostic and therapeutic possibilities, to intraoperatively localize and control the obscure GI bleeding source, may be also a challenging task (8). Moreover, even with a preoperative localization using selective angiography, the intraoperative precise confirmation of the bleeding origin may be difficult.

Therefore, any progress to support the prompt mapping followed by an accessible and efficient control of the haemorrhage is important.

Indocyanine Green (ICG), known also as Fluorescein, was used in ophthalmology since the 70 s and later introduced for diagnostic purposes in various medical domains. ICG solution is injected in the circulation, binds with blood plasma and in 3-5 minutes runs in the bloodstream. Its fluorescence may be observed in real time using special infrared system cameras as a real time angiography.

Near-Infrared (NIR) Indocyanine Green (ICG) fluorescence is being recognized as a critical upgrade to the intraoperative decision making in surgery (9).

The idea of using ICG to identify the site of an obscure enteral bleeding was recently introduced $(10,11)$. An intraarterial catheter is preoperatively introduced into the superior mesenteric artery and progressed to the branches of the bowel suspected to include the bleeding source. A selective ICG angiography is intraoperatively performed and using a NIR equipped laparoscope, the site of the haemorrhage is confirmed $(10,11)$.

This technique follows the principles of a similar procedure but using Methylene Blue
(12-14) and, requires preoperative angiographic assessment of the bleeding site and complementary gestures of interventional radiology (15).

On the other hand, the endoluminal explorations made significant progress to identify the bleeding origin. Using an infrared endoscopic system and flushing the hemorrhagic site with ICG solution, a successful real-time visualization of the bleeding points was demonstrated during the endoscopic procedures (16).

However, all the described surgical techniques to identify the obscure GI bleeding are speculating only the early phases of the ICG metabolism (17), analyzing the transitory presence of the dye in the blood vessels. Our idea was to trace the ICG when it is abnormally going out from the circulation, targeting the bleeding sites, where it will be accumulated and observed for a longer time interval. These bleeding sites may not be evident in the ICG distribution phase but, be promptly observed 20-30 minutes after the intravenous injection, when the circulating dye will be washed out by the liver. To our knowledge, an open or laparoscopic exploration, using infrared technology to map the site of the GI bleeding after the ICG clearance from the bloodstream, was never used before.

The aim of our study was to explore the feasibility and the effectiveness of a novel IGC fluorescence-guided post dye circulation washout laparoscopic technique to localize the obscure GI haemorrhage (Laparoscopic postICG-Bleeding Mapping).

\section{Method}

The feasibility study was IRB approved, in 2020 and included patients admitted in our institution with obscure overt GI bleeding, who previously underwent surgical modifications of the gut architecture (gastrointestinal bypasses). The patients were admitted in the Intensive Care Unit (ICU) for monitoring. After resuscitation and blood transfusion, extensive investigations to localize the site of the GI bleeding, including upper endoscopy, 
colonoscopy and, CT angio-graphy should be performed, iteratively if necessary. Videocapsule endoscopy (VCE) was not considered due to the obstructive risks related to the history of abdominal surgery whilst double balloon endoscopy (DBE) was not available.

As a result of the extensive diagnostic workup, the bleeding source may be identified, or it may continue to be unknown. Whenever the bleeding source is localized and an endoscopic or radiologic approach to control the hemorrhage can be accessed and achieved, the patients are referred for the prompt specific therapy and excluded from the study.

If the GI bleeding remains obscure or the bleeding site is inaccessible for the nonsurgical methods, we proposed Laparoscopic post-ICG-Bleeding Mapping.

We planned to act similarly, in the patients needing urgent identification and control of the GI bleeding, before completing or repeating the relevant investigations. A typical example for this category are patients presenting with overt GI bleeding and negative endoscopy, an inconclusive colonoscopy (due to massive presence of bloody faeces), with the bleeding source also undetected during CT angiography. The anaemia and the clinical evolution may not give time for bowel preparation or to repeat any of the investigations and, the Laparoscopic post-ICG-Bleeding Mapping is proposed.

\section{Operative Room set up}

The operative room (OR) dedicated to Laparoscopic post-ICG-Bleeding Mapping should be equipped as a hybrid facility for minimally invasive technologies. Besides the laparoscopic equipment, ready for advanced video-assisted procedures, an integrated or dedicated infra-red technology system to capture the fluorescent ICG, is mandatory. An endoscopic tower prepared for any endoluminal haemostasis techniques and connected to a $\mathrm{CO} 2$ insufflator, will be ready to act complementary to laparoscopic surgery, for the confirmation and controlling of the bleeding source. Finally, a mobile radiological system (i.e. C-Arm), to support the interven- tional radiology procedures and, if needed, to facilitate the endoscopic maneuvers, will complete the OR setting.

\section{Laparoscopic Technique}

General anesthesia with oro-traheal intubation is required for the Laparoscopic post-ICGBleeding Mapping. The patient is placed in dorsal decubitus with the legs in abduction ("French position") and secured on the operating table, to allow its safe mobilization (Trendelenburg, reverse-Trendelenburg or any lateral tilt) and permit the intraoperative transanal endoscopic access.

A Veress needle or an open access technique is used to create the $\mathrm{CO} 2$ pneumo-peritoneum. The position of the optical and working trocars is customized relative to the previous abdominal surgeries' scars and adhesions. A 30-degree endoscope is recommended for this procedure. Minimal but adequate laparoscopic adhesiolysis will be performed to have proper access to all the intestinal segments and a clear understanding of the surgical anatomy. Intraoperative endoscopy with gas insufflation and trans-illumination can be useful to improve the understanding of the gut surgical modifications of the normal anatomy. The exploration may reveal blood content in the small and/or large bowel and, sometimes can indicate the suspected site of the bleeding.

At this stage, $5 \mathrm{ml}$ of Indocyanine Green aqueous solution (Verdye ${ }^{\circledR}, 5 \mathrm{mg} / \mathrm{ml}$, Diagnostic Green, Germany) are intravenously injected and the OR timer is started. The videoendoscope will be switched on infra-red mode, ready to visualize the fluorescent signal. In $3^{-}$ 5 minutes, the dye will record a maximal intensity of the signal and, 15 to 30 minutes after it will be eliminated from the bloodstream (18). Half an hour after the ICG intravenous administration, the dye will be almost completely washed-out from the circulation and it should be present only in the liver and, at any and each bleeding site, mapping the origin of the haemorrhage.

If the technique is applied in patients with no history of abdominal surgery, expecting no 
adhesions and facile manipulation of the bowel, the ICG can be injected at the induction time of the anesthesia and the OR timer is started. Thus, the dye wash-out phase will occur while the NIR laparoscopic exploration will be set up, saving time until the bleeding site will be confirmed.

As soon as the suspected area of bleeding is localized by the ICG, a careful inspection of the bowel, by a cranially progressing manipulation, should search for the disorder responsible for the haemorrhage. If no clue is offered, a laparoscopic or laparoscopic assisted endoscopic endoluminal inspection of the targeted digestive segment (stomach or bowel) should be performed to identify the exact cause of the GI bleeding. After collecting all the information, an endoscopic, laparoscopic, or open surgery approach will be decided and performed to achieve adequate haemostasis. These techniques may be conservative (i.e. endoscopic clipping, small tumour resection, coagulation or use of argon plasma) or surgical excisions (i.e. bowel resection).

\section{Results}

The IGC fluorescence-guided post dye washout laparoscopic technique (Laparoscopic postICG-Bleeding Mapping) was used to localize the obscure GI bleeding in a series of two patients.

Case 1. A 43-year old male, who received a Laparoscopic Roux-en-Y gastric bypass (RYGBP) two days before, developed a GI bleeding with haematochezia and haemoglobin drop (from 14.2 to $8.8 \mathrm{mg} / \mathrm{dl}$ ) before his discharge. The bariatric surgery procedure was indicated for morbid obesity (BMI of 46 $\mathrm{kg} / \mathrm{m}^{2}$ ), type $2 \mathrm{DM}$ and metabolic syndrome, and antithrombotic prophylaxis was postoperatively initiated (Fragmin 7500 UI twice per day). The initial postoperative evolution was uneventful and after presenting the signs of GI bleeding, he was transferred to ICU for resuscitation and blood transfusions.

The upper GI tract endoscopy as well as CT angiography were unable to identify an active bleeding source. No clot or abnormal bowel dilation was described at the CT scan. Moreover, the patient presented more episodes of haematochezia and the haemoglobin dropped to $6.6 \mathrm{mg} / \mathrm{dl}$ despite the blood transfusions.

We have noticed that no history of colonoscopy was encountered. Considering the bleeding risk of the high doses of antithrombotic therapy on unknown intestinal disorders, a colonoscopy was proposed. However, the information was limited by the massive presence of digested blood in the rectum.

Evaluating the clinical situation, the potential evolution to haemorrhagic shock and the conclusion of the investigations, the patient's condition was qualified as an acute obscure GI bleeding with the need of urgent control of the haemorrhage. Therefore, we have decided to laparoscopically reexplore the abdomen to identify the bleeding source and perform the haemostasis.

The previously IRB approved protocol of ICG fluorescence-guided post dye circulation wash-out laparoscopic technique was considered to localize the site of the acute obscure GI haemorrhage.

The procedure was following the steps described above. Expecting no postoperative adhesions and an easy access to entire digestive track, $5 \mathrm{ml}$ of ICG was intravenously injected during induction of general anesthesia and start the timer. Laparoscopic inspection was initiated 22 minutes after injection, just before the dye wash-out of the circulation.

Carefully inspection using an endoscope with NIR technology (NOVADAQ, US) demonstrated no fluorescent signal at the level of colon, JJA, common and alimentary loops. At the proximal segment of the biliopancreatic loop an intense ICG florescence signal was demonstrated (Fig. 1). This was indicating that the haemorrhage may be originated from the gastric remnant. Indeed, post dye wash-out intense signal was demonstrated at the level of duodenum but weaker at the gastric remnant.

The laparoscopic trans-gastric exploration of the remnant identified an active bleeding 

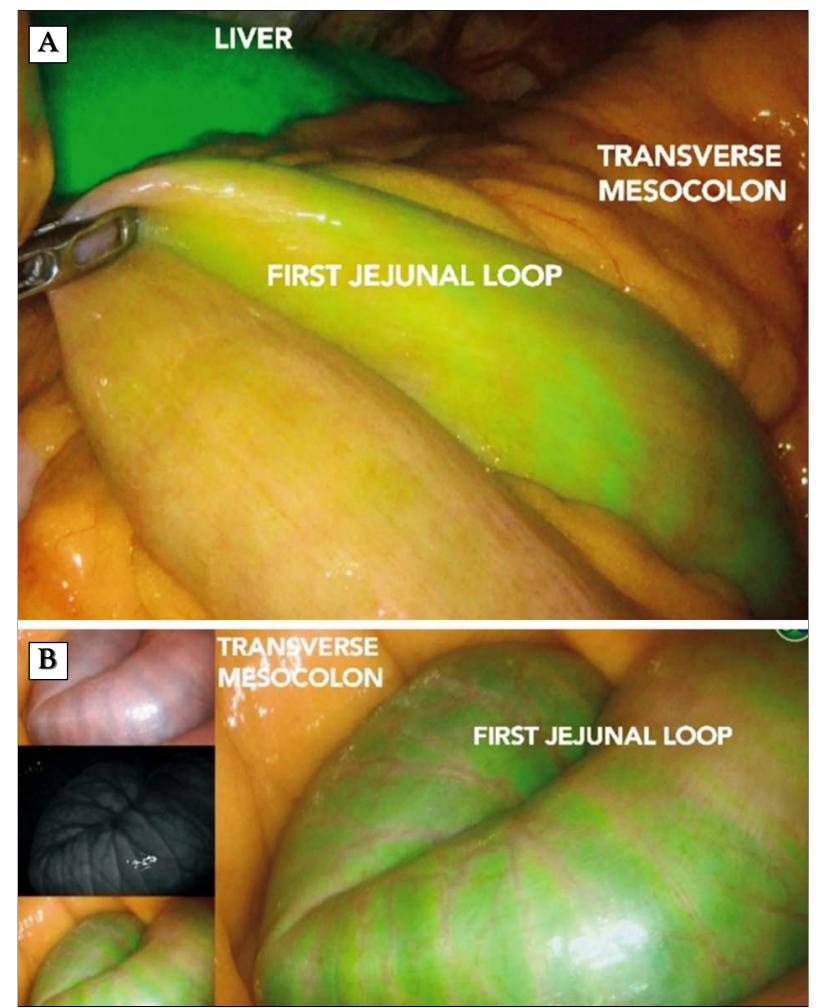

Figure 1. Postoperative endoluminal hemorrhage after laparoscopic RYGBP. (A) ICG guided infra-red laparoscopymappedindicated intense signal al the first jejunal loop. (B) The dye is eliminated from the circulation(wash-outphase)and the fluorescent blood fills the enteral lumen.

source siding the stapled line (Fig. 2). Haemostasis was achieved with laparoscopic ligation using resorbable stitches. Closing the gastric access was achieved by continuous suture (Fig. 3).

Time of surgery was 90 minutes, and the intraoperative blood loss was minimal. Hospital stay was 3 postoperative days.

Case 2. A 66-year old male patient who underwent an open Whipple resection for pancreatic adenocarcinoma nine months before, was admitted in our institution for a GI bleeding. Known with permanent atrial fibrillation for 12 years, treated with Eliquis 5 $\mathrm{mg}$ twice a day and Atenolol $50 \mathrm{mg}$ twice a day, the patient presented to the Emergency Room (ER) for melena, asthenia and dyspnea. At the initial assessment, the patient was stable, with no abdominal pain, while the rectal examination confirmed the presence of melena. His

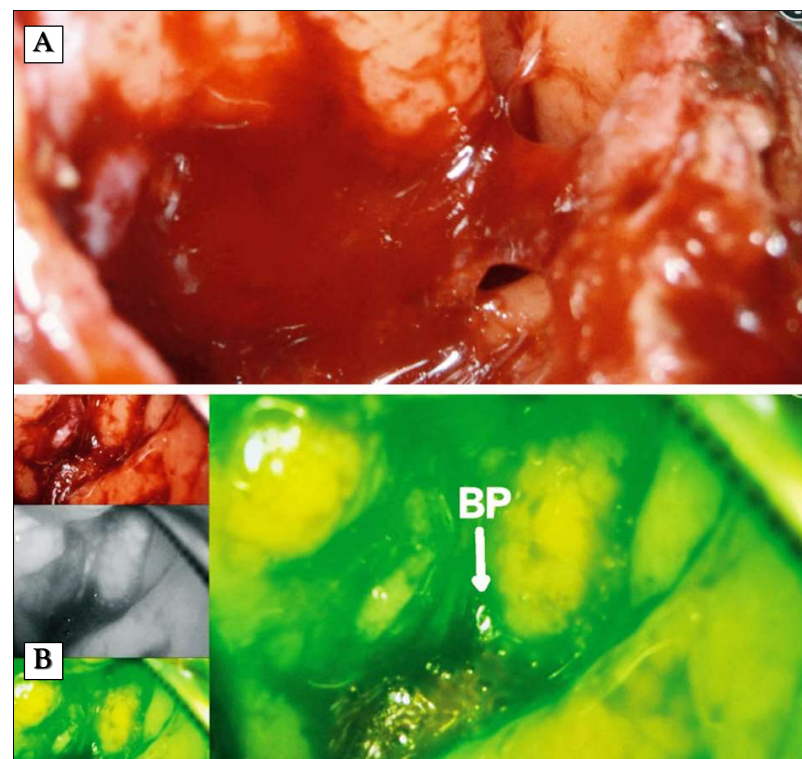

Figure 2. Gl Bleeding following RYGBP. (A) Clots and fresh blood was observed after laparoscopic gastrotomy (B) After reinjecting ICG the bleeding point (BP) was evident at the stapled line

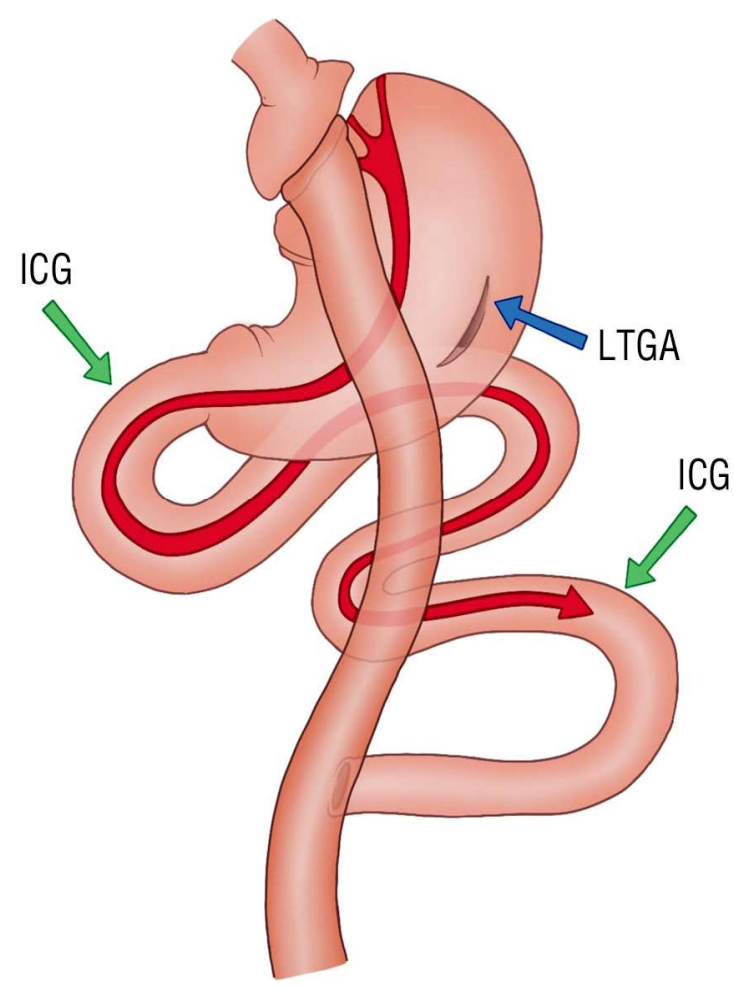

Figure 3. GI Bleeding following RYGBP.

Schematic representation of the laparoscopic transgastric exploration and hemostasis.

Red Arrow - the blood flow originated from stomach; Green arrow - fluorescent signal after ICG wash-out; blue arrow - laparoscopic trans-gastric access (LTGA). 


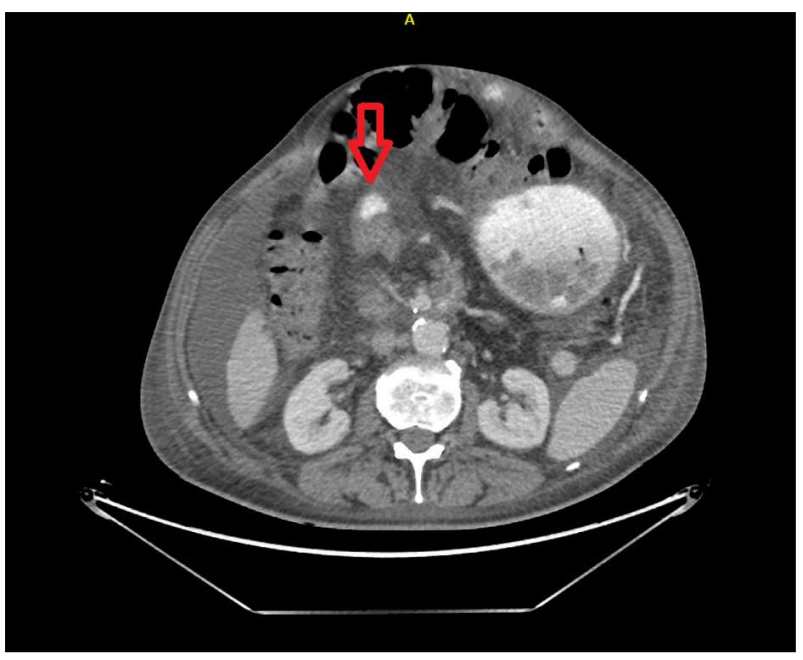

Figure 4. Obscure bleeding from the Biliopancreatic loop after open Whipple's Procedure - CT scan

initial blood pressure was $98 / 65 \mathrm{mmHg}$, with tachycardia $102 \mathrm{bpm}$ and the laboratory data revealed anemia with hemoglobin $6.3 \mathrm{~g} / \mathrm{dL}$.

CT angiography indicated a possible active bleeding from a jejunal loop close to the gastro-jejunal anastomosis (Fig. 4). The endoscopic evaluation was decided. The upper digestive endoscopy was performed, using a long pediatric endoscope. Gastric stasis was observed, with small fresh blood clots. Gastric mucosa was washed and inspected afterward in optimal conditions, without identifying any source of bleeding or any suspicious lesion. The anastomosis was normal and large. The efferent jejunum was inspected for about 30 $\mathrm{cm}$ and it showed no sign of bleeding. The afferent jejunum was also inspected, on the whole length, without blood into the lumen. Siding, the choledoco-jejunostomy an area of angioectasia was observed without any recent bleeding sign. Colonoscopy was attempted but remained irrelevant due to the massive rectal presence of digested blood mixed with feces.

The patient was closely supervised in the ICU and received repeated transfusions. Despite the medical therapy, he presented more episodes of hematochezia and a persistent decrease in hemoglobin.

The interdisciplinary medical board decided to repeat the CT angiography and to initiate colon preparation with enemas and perform a proper colonoscopic evaluation.

The CT angiography did not identify any active source of bleeding, while the initial suspicion of a gastro-jejunal source could not be confirmed, neither. Moreover, the interpretation of the radiologist suspected a possible hemorrhage at the level of the right colon, enlarging and not narrowing the area of potential bleeding. Before completing the preparation for colonoscopy, signs of an active upper GI bleeding re-occurred, as the naso-gastric aspirate became bloody and hemoglobin decreased down to $5.1 \mathrm{~g} / \mathrm{dL}$ (despite repeated transfusions).

Based on the collected information, the condition was qualified as an overt obscure GJ bleeding with an urgent need to be localized and controlled. Therefore, a hybrid approach, endoscopic and laparoscopic post-ICG-Bleeding Mapping was decided to be performed in the OR. Under general anesthesia, the laparoscopic exploration required minimal adhesiolysis and revealed the postoperative gut changes after Whipple procedure. The biliopancreatic loop reached the stomach $40 \mathrm{~cm}$ distally, on an end-to-site gastro-jejunal anastomosis and the small bowel and colon were filled with bloody content.

$5 \mathrm{ml}$ of ICG were intravenously injected and the OR timer was started.

An iterative endoscopy was intraoperatively performed while the common jejunal loop was occluded with a grasping forceps to prevent the $\mathrm{CO} 2$ bowel distension. The endoscopy identified only a small oozing ulceration at the gastrojejunal anastomosis. Hemostasis was achieved with clips and adrenaline solution injected in the anastomotic mucosa. A naso-jejunal tube was positioned inside the afferent loop.

Half an hour after the ICG intravenous administration, the peritoneal cavity was inspected by means of a 30-degree endoscope and a NIR system (NOVADAQ ${ }^{\circledR}$, US). The dye was completely washed-out from the circulation and it was retained in the liver. The small bowel and the colon were not presenting fluorescent signal except for the biliopancreatic loop (Fig. 5 A). The detailed inspection of the biliopancreatic limb noticed a more intense 

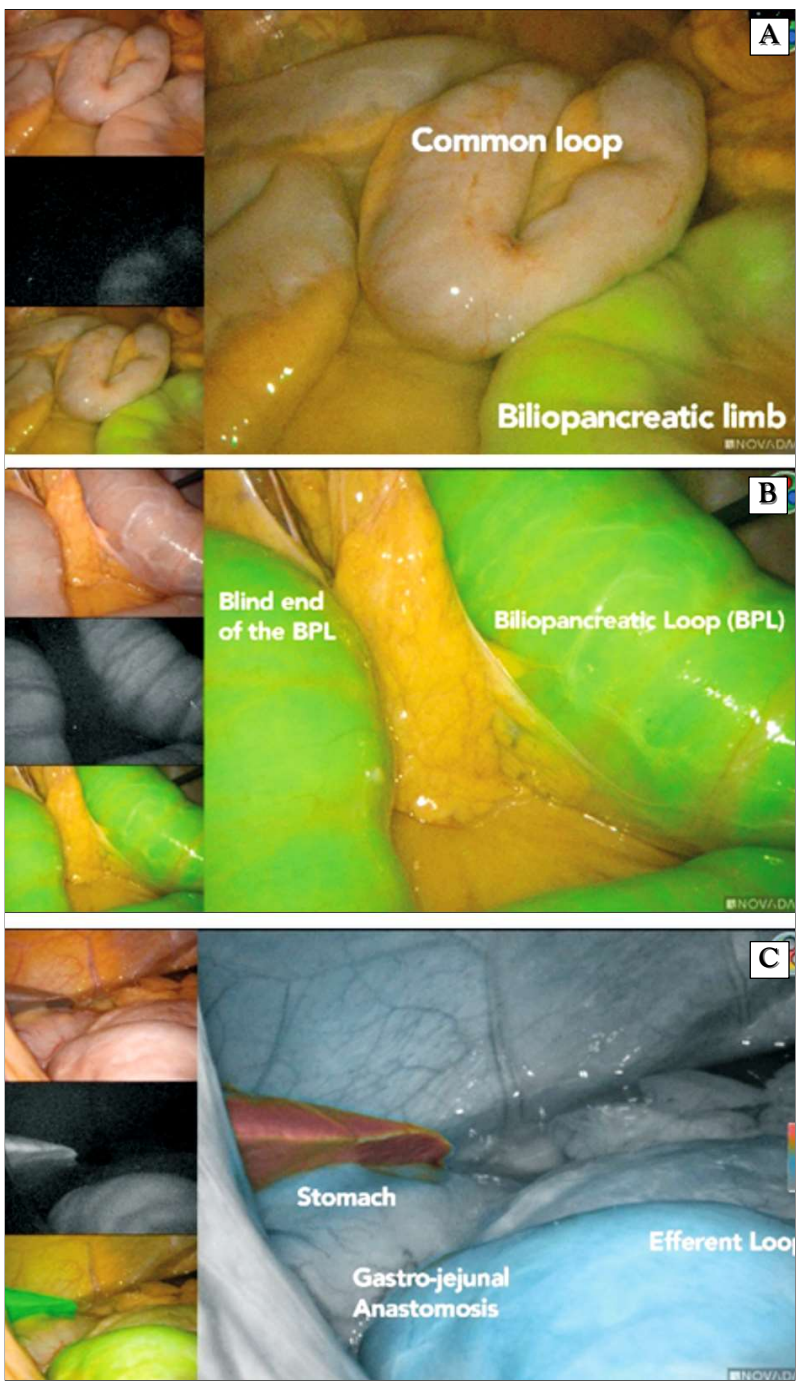

Figure 5. Obscure bleeding from the Biliopancreatic loop after open Whipple's Procedure. (A) ICG guided

laparoscopic localization of the bleeding site after dye wash-out. ICG is present in the biliopancreatic limb and not in the common loop; (B) Intense signal at the level of biliopancreatic loop. (C) Loop gastro-jejunal anastomosis. ICG Florescence indicates blood in biliopancreatic limb. Retained in the liver.

fluorescent signal toward the enteral proximal end (Fig. 5 B). Weak signal was noticed at the gastric level while at the gastro-jejunal anastomosis, the enteral site demonstrated a significant blood presence (Fig. 5 $C$. It was concluded that the stomach was contaminated with blood coming from the biliopancreatic limb. Further inspection of the common loop revealed that the blood

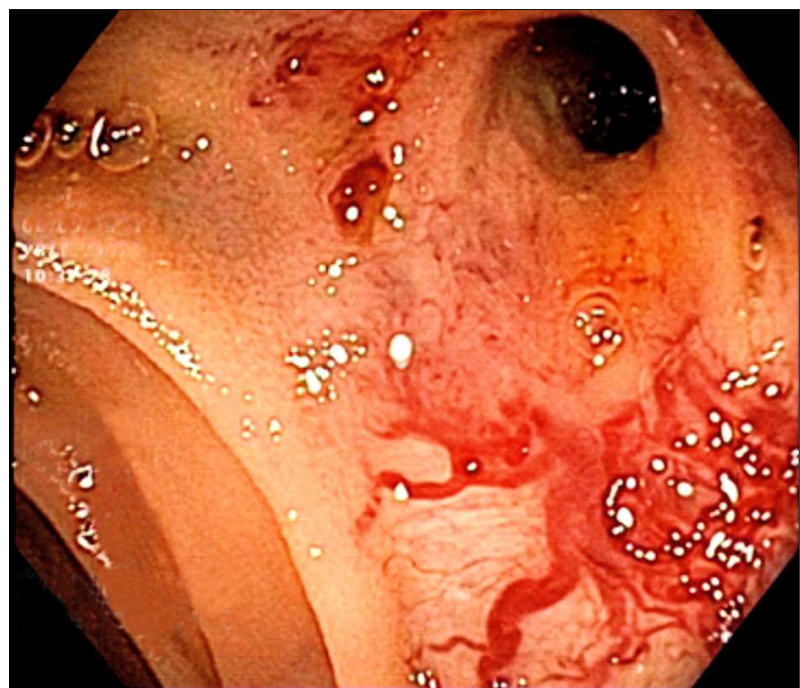

Figure 6. Obscure bleeding from the Biliopancreatic limb 1 year after open Whipple's Procedure. Endoscopic view of angiodysplasia siding the choledocho-jejunal anastomosis

flow had a limited progression from the gastro-jejunal anastomosis.

Ten minutes after initiating the laparoscopic infrared inspection and, 40 minutes after the ICG intravenous injection, the obscure GI bleeding was mapped at the proximal end of the biliopancreatic jejunal loop. An endoscopic approach was decided to control the jejunal bleeding. Upper GI tract endoscopy with an $160 \mathrm{~cm}$ Olympus GIFH190 Exera 3 endoscope progressed along the biliopancreatic loop with laparoscopic assistance and confirmed the presence of an active bleeding source from angiodysplasia siding the choledoco-jejunal anastomosis (Fig. 6). Argon plasma coagulation was performed endoscopically and local hemostasis was achieved.

Time of surgery was 70 minutes, and the intraoperative blood loss was minimal. Hospital stay was 5 postoperative days.

Analysing the two presented cases, no mortality or specific morbidity was associated to the procedure.

Statistical Analysis - due to the limited number of cases, no statistical evaluation has been performed for this study yet but, all the data is stored in a dedicated database to follow the patients' evolution. 


\section{Discussions}

Gastrointestinal (GI) bleeding may be a lifethreatening complication and adequate control of the hemorrhage is mandatory. GI bleeding is classified as overt or occult. Overt GI bleeding, known as acute bleeding, is macroscopically observable, such as hematemesis, hematochezia or melena, while occult GI bleeding is not visible to the patient or physician, manifested as a positive fecal occult blood test (FOBT) or iron deficiency anemia, with or without a positive FOBT (5). Obscure GI bleeding was defined as a recurrent bleeding of unknown origin, in which the source is not identified after upper endoscopy and colonoscopy. Obscure bleeding may be either overt or occult $(1,3,5,6)$.

Obscure GI bleeding used to comprise approximately $5 \%$ of patients presenting with all gastrointestinal (GI) hemorrhage (19). As the modern diagnostic imaging and endoscopic techniques may identify more of the GI bleeding sources, the range of the obscure GI bleeding tent to narrow. Video-capsule endoscopy, double balloon endoscopy, CT angio-graphy, magnetic resonance angiography (MRA), angiography or red cell scintigraphy are used complementary to classical endoscopic explorations and are successfully identifying the bleeding sources in $41-75 \%$ of the patients with obscure GI bleeding (4). Moreover, consecutive endoscopic and radiological guided hemostatic techniques are efficiently controlling the bleeding (3).

Therefore, the American College of Gastroenterology (ACG) proposed that the term obscure GI bleeding to be reserved for patients in whom the source cannot be identified anywhere in the GI tract even with the latest imaging modalities (20).

On the other hand, in a real-life case scenario, the above-mentioned extensive diagnostic work-up is not feasible for a significant number of patients with obscure GI bleeding. Either the patient's clinical status is critical and may not give time to run all the diagnostic protocols or the hospital where the patient was urgently admitted can offer a limited access to all modern investigations, the term obscure GI bleeding may continue to be used in the traditional way, (4). as we have decided for the present study.

As the GI bleeding remains obscure, no proper control of the hemorrhage can be planned. If the clinical situation goes worse, performing surgery to identify and control the bleeder may be considered as a next level option. However, the surgical localization of the GI bleeder may a difficult task, if the haemorrhagic lesion is not evident. The recommendations to use surgery for obscure GI bleeding specify that the source of bleeding should be carefully localized before resection (8).

The task here is to develop a technique to easy and promptly identify the bleeding source and give rapid and efficient access to control the hemorrhage.

The use of Methylene blue (Asmethylthioninium Chloride) to intraoperatively mark the bleeding site is a technique introduced in the 80's (12) and it is considered a fairly simple and quick process, compared with visually trying to identify the source of bleeding (13). However, to obtain the enteric mapping, a preoperative super-selective mesenteric angiography (SSMA) is needed, and $0.5 \mathrm{~mL}$ of methylene blue $(10 \mathrm{mg} / \mathrm{mL})$ is intra-operatively injected using a microcatheter progressed in the small arterial branches of the enteral area of concern $(14,21)$. As a result, the respective segment of bowel is colored thus allowing to perform a selective enteral resection (14).

Methylene blue is also used in breast surgery to identify sentinel lymph nodes, to detect metastatic disease and in colorectal surgery. Headache, vomiting, confusion, shortness of breath, and high blood pressure are the most common side effects (13).

Indocyanine green (ICG) was introduced to map the enteral bleeding since the 90's and the method was following the same approach. A SSMA is preoperatively performed and the suspected bleeding site is intraoperative localized using fluorescein (22). ICG is associated with no side effects but, the intraoperative visualization of the fluorescent dye requires a NIR equipped endoscope $(10,11)$. Similarly, the benefit of the technique is relat- 
ed to the limitation of the bowel resection, even in hemodynamically unstable patients (15).

Identifying the bleeding source is also a task for the endoscopic techniques and significant progress has been encountered over the last decade. Using an infrared endoscopic system, the bleeding-points may be detected after flushing the endoluminal hemorrhagic area with ICG solution (16).

More recently, a novel image-enhanced endoscopic technology called red dichromatic imaging (or dual red imaging) was proposed for detecting exposed blood vessels in the gut. This techno-logy may prevent the delayed bleeding after gastric endoscopic exploration (23) or the bleeding in colonic diverticular disease (24).

But all the above-mentioned techniques require the preoperative or endoscopic identification of the bleeding site or at least of an area of concern, which is not the case for many obscure GI bleedings.

Both surgical mapping procedures described before require preoperative SSMA (not always a simple task) and the real-time visualization of the dye progression. If this cannot be achieved in due time, methylene blue infiltrates the surrounding tissue while ICG may be distributed in the entire circulation and, if the suspected area is not bleeding there will be no signal in the area after washout. Both situations may alter the expected outcome to map the obscure GI bleeding site.

Considering these possible problems, we imagined a novel approach to identify the obscure GI bleeding which is not speculating the early phases of the ICG metabolism, but the late ones (25). Our method is tracking the ICG at the GI bleeding site using laparoscopic infra-red technology to visualize the fluorescent dye in the gut after the ICG clearance from the bloodstream (dye wash-out).

ICG is an inert, water-soluble, fluorescent tricarbocyanine, which binds tightly to blood plasma immediately after intravenous injection $(25,26)$ and, it is uniformly distributed in the circulation within 2 to $3 \mathrm{~min}$ (27). Volume of distribution is very close to plasma volume and half-life is very short (3 to $5 \mathrm{~min}$ ), longer in case of hepatic dysfunction). Extraction from the blood occurs almost exclusively by the liver, therefore ICG is excreted unchanged and almost completely (97\%) into the bile in a non-conjugated form. Twenty to thirty min are usually needed for the transition from the distribution to the elimination phase $(27,28)$.

Among its various applications in ocular surgery, neurosurgery, cardiovascular surgery, plastic surgery and cancer surgery, ICG is mostly used to evaluating the tissue blood perfusion or tracking the dye in the lymphatic tree or bile (29).

In GI surgery, ICG is currently used in colorectal surgery $(30,31)$, esophageal surgery $\left(32^{-}\right.$ 34 ), mostly to control the risk of anastomotic leakage or to evaluate the intestinal perfusion $(35,36)$. But only few studies are using ICG to map the bleeding and only with a preoperative SSMA (13). One of the explanations may be related to the combination of the fluorescent signal at the area of bleeding and, in the circulation, producing visual confusion and significantly limiting the infrared light evaluation. But, in our protocol, we explore the digestive track in infrared light after the dye wash-out from the circulation, therefore being able to capture only the signal from the bleeding site, and, of course from the liver.

This was demonstrated in both our cases included in the feasibility study, in whom the GI bleeding had an unknown origin. The vascular branches of the small bowel may be observed without any signal, while the fluorescence blood can be seen from inside. (Fig. $1 B$ and 5B) In both cases, after the ICG administration, in a relatively short time, 22 and 40 minutes, respectively, the bleeding source was identified and was soon after controlled.

It is to be mentioned that the timing is very important for this procedure. A too early exploration may still observe remnant dye in the bloodstream while a too late one, may notice an extended presence of the fluorescent blood in the bowel, enlarging instead of narrowing down the gut area of concern.

Early postoperative GI bleeding is an infrequent complication (1-3.8\%) after Roux-en-Y Gastric Bypass (RYGBP) (37), it is mostly 
originated for the gastro-jejunal (GJA) or jejuno-jejunal anastomosis (JJA) and the treatment is conservative in most of the cases (38). In our case the endoscopy was negative for GJA and no indirect sign of a JJA bleeding was demonstrated. A colonic bleeding was considered and not excluded by a tentative colonoscopy. The laparoscopic post ICG bleeding mapping was efficiently indicating that the haemorrhage may be originated from the gastric remnant (Fig. 1). Consecutive laparoscopic trans-gastric haemostasis was promptly performed.

We found a limited number of cases published on GI Bleeding from the Remnant in RYGBP, managed by Angiography (39) or double balloon endoscopy (40) and our method may be suitable for some of these situation.

Choledocojejunal bleeding after hepatobiliary-pancreatic surgery is a rare finding, and it is equally subtle to diagnose and to treat. Ectopic jejunal bleeding occurring after liver surgery (41-43) or after Whipple procedures $(44,45)$ is usually siding the bilioenteric anastomosis (BEA). The position of the BEA at the blind end of the afferent jejunal limb makes it more difficult to reach and treat endoscopically $(12,13)$. In our case, the biliopancreatic loop could be endoscopically explored but, as explained before, the GI bleeding remained obscure.

Using the laparoscopic post-ICG wash-out mapping, the bleeding source was promptly identified overcoming the limitations of the preoperative diagnostic methods.

As a differential diagnosis for bleeding at this site, both angiodysplasia and ectopic jejunal varix should be considered.

While angiodysplasia lesions are more superficial, involving the mucosa, jejunal varix tend to become larger and involve the submucosa. Therapy for ectopic variceal bleeding aims to obliterate the varices by endoscopic sclerotherapy or ligation, radiologic embolization, (46), laparotomy-assisted transcatheter variceal embolization (45) or surgical re-anastomosis (46), while angiodysplasia and small varices are efficiently controlled with argon plasma. In our case we could efficiently use argon plasma coagulation (APC) as no significant portal hypertension was noticed.

We appreciate the IGC fluorescence-guided post dye circulation wash-out laparoscopic technique to localize the obscure GI haemorrhage. (Laparoscopic post-ICG-Bleeding Mapping) as simple and efficient MIS method, especially for the patients with negative angiography of limited access to the preoperative SSMA. It was used in 2 cases of overt GI bleeding and history of abdominal surgery but, it may be potentially used in occult GI bleedings and in patients with no surgical change of the gut anatomy, too.

To our knowledge the Laparoscopic postICG-Bleeding Mapping was never used before and we see its potential to identify a wide range of GI bleeding sources, originated form colorectal, small bowel, or gastric lesions.

The method might have some limitations as it is based on a qualitative evaluation of the bleeding area while the outcome is depending on the bleeding flow and time of dye wash-out. Moreover, our study included a limited number of cases so far, but more conclusions are expected from future evaluations of the method.

\section{Conclusion}

A successful novel ICG fluorescence-guided laparoscopic mapping technique was used to localize the site of the obscure GI haemorrhage and to facilitate the prompt bleeding control. To the best of our knowledge these are the first published cases for which this technique was used. The feasibility of the method to other challenging GI tract bleedings should be further studied.

\section{Conflict of Interest}

The authors declare no conflict of interest.

\section{Ethical Approval}

All procedures performed in the study were in accordance with the ethical standards of the 1964 Helsinki Declaration and its 
later amendments or comparable ethical standards.

\section{Acknowledgement}

The drawing is performed by Filip Mihnea Copaescu.

\section{References}

1. Kim BSM, Li BT, Engel A, Samra JS, Clarke S, Norton ID, et al. Diagnosis of gastrointestinal bleeding: A practical guide for clinicians. World J Gastrointest Pathophysiol. 2014;5(4):467-78.

2. Jones S, May AK. Postoperative gastrointestinal hemorrhage. Surg Clin North Am. 2012;92(2):235-42, viii.

3. Murphy B, Winter DC, Kavanagh DO. Small Bowel Gastrointestina Bleeding Diagnosis and Management-A Narrative Review. Front Surg. 2019;6:25.

4. Ohmiya N. Management of obscure gastrointestinal bleeding Comparison of guidelines between Japan and other countries. Dig Endosc. 2020;32(2):204-218. Epub 2019 Nov 25.

5. Bull-Henry K, Al-Kawas FH. Evaluation of occult gastrointestina bleeding. Am Fam Physician. 2013;87(6):430-6.

6. Raju GS, Gerson L, Das A, Lewis B, American Gastroenterological Association (AGA). Institute medical position statement on obscure gastrointestinal bleeding. Gastroenterology. 2007;133(5):1694-6.

7. Kochhar GS, Sanaka MR, Vargo JJ. Therapeutic management options for patients with obscure gastrointestinal bleeding. Therap Adv Gastroenterol. 2012;5(1):71-81.

8. Strate LL, Gralnek IM. ACG Clinical Guideline: Management of Patients With Acute Lower Gastrointestinal Bleeding. Am J Gastroenterol. 2016;111(4):459-74.

9. Alander JT, Kaartinen I, Laakso A, Pätilä T, Spillmann T, Tuchin VV et al., A review of indocyanine green fluorescent imaging in surgery. Int J Biomed Imaging. 2012;2012:940585.

10. Liu YY, Pop R, Diana M, Kong SH, Lègner A, Beaujeux R, et al. Realtime fluorescence angiography by intra-arterial indocyanine green injection to identify obscure gastrointestinal bleeding territory: proof of concept in the porcine model. Surg Endosc. 2016;30(5): 2143-50. Epub 2015 Aug 15.

11. Ono H, Kusano M, Kawamata F, Danjo $Y$, Kawakami M, Nagashima $\mathrm{K}$, et al. Intraoperative localization of arteriovenous malformation of a jejunum with combined use of angiographic methods and indocyanine green injection: Report of a new technique. Int J Surg Case Rep. 2016;29:137-140.

12. Athanasoulis CA, Moncure AC, Greenfield AJ, Ryan JA, Dodson TF. Intraoperative localization of small bowel bleeding sites with combined use of angiographic methods and methylene blue injection. Surgery. 1980;87(1):77-84

13. Bhuller SB, Lieser M, Ismail N, Woods B. Obscure gastrointestinal bleeding localization using preoperative super-selective mesenteric angiography and intraoperative methylene blue injection: A case report and literature review. Int J Surg Case Rep. 2019;65:69-72.

14. Gifford SM, Peck MA, Reyes AM, Lundy JB. Methylene blue enteric mapping for intraoperative localization in obscure small bowel hemorrhage: report of a new technique and literature review: combined intraoperative methylene blue mapping and enterectomy. J Gastrointest Surg. 2012;16(11):2177-81.

15. Kawachi J, Ogino H, Shimoyama R, Ichita C, Isogai N, Murata T, et al., Intraoperative angiography with indocyanine green injection for precise localization and resection of small bowel bleeding. Acute Med Surg. 2020;7(1):e549.

16. Ishihara R, lishi H, Kidu T, Yamamoto S, Miyoshi R, Inoue T, et al.,
Infrared endoscopic system for bleeding-point detection after flushing with indocyanine green solution (with videos). Gastrointest Endosc. 2008;68(5):975-81.

17. Hyo T, Matsuda $\mathrm{K}$, Tamura $\mathrm{K}$, Iwamoto $\mathrm{H}$, Mitani $\mathrm{Y}$, Mizumoto $\mathrm{Y}$, et al. Small intestinal arteriovenous malformation treated by laparoscopic surgery using intravenous injection of ICG: Case report with literature review. Int J Surg Case Rep. 2020;74:201-204.

18. Karanicolas PJ, Chapter 3 - Assessment of hepatic function: Implications for the surgical patient, in Blumgart's Surgery of the Liver, Biliary Tract and Pancreas, 2-Volume Set (Sixth Edition), W.R. Jarnagin, Editor. 2017, Elsevier: Philadelphia. p. 60-65.e2.

19. Szold A, Katz LB, Lewis BS. Surgical approach to occult gastrointestinal bleeding. Am J Surg. 1992;163(1):90-2; discussion 92-3.

20. Gerson LB, Fidler JL, Cave DR, Leighton JA. ACG Clinical Guideline: Diagnosis and Management of Small Bowel Bleeding. Am J Gastroenterol. 2015;110(9):1265-87; quiz

21. Pai M, Frampton AE, Virk JS, Nehru N, Kyriakides C, Limongelli P, et al., Preoperative superselective mesenteric angiography and methylene blue injection for localization of obscure gastrointestinal bleeding. JAMA Surg. 2013;148(7):665-8.

22. Ohri SK, Jackson J, Desa LA, Spencer J. The intraoperative localization of the obscure bleeding site using fluorescein. J Clin Gastroenterol. 1992;14(4):331-4.

23. Miyamoto S, Sugiura R, Abiko S, Hatanaka K, Yamamoto $Y$, Naruse $\mathrm{H}$, et al. Red dichromatic imaging helps in detecting exposed blood vessels in gastric ulcer induced by endoscopic submucosal dissection. Endoscopy. 2020 Dec 17. Online ahead of print.

24. Saino M, Aoyama T, Fukumoto A, Shigita K, Asayama N, Mukai S, et al. Tracking the target in colonic diverticular bleeding using red dichromatic imaging. Endoscopy. 2021 Jan 27. Online ahead of print.

25. Ohtsubo S, Kusano M. Indocyanine Green Fluorescence Properties, in ICG Fluorescence Imaging and Navigation Surgery, M. Kusano, et al., Editors. Springer Japan: Tokyo; 2016, p. 9-20.

26. Ohtsubo KMS, Shimada S. Basic Aspects of ICG Fluorescence Imaging of the Liver, in ICG Fluorescence Imaging and Navigation Surgery, M. Kusano, et al., Editors. Springer Japan: Tokyo; 2016, p. $273-280$

27. De Gasperi A, Mazza E, Prosperi M. Indocyanine green kinetics to assess liver function: Ready for a clinical dynamic assessment in major liver surgery? World J Hepatol. 2016;8(7):355-67.

28. Halle BM, Poulsen TD, Pedersen HP. Indocyanine green plasma disappearance rate as dynamic liver function test in critically ill patients. Acta Anaesthesiol Scand. 2014:58(10):1214-9.

29. Schols RM, Connell NJ, Stassen LP. Near-infrared fluorescence imaging for real-time intraoperative anatomical guidance in minimally invasive surgery: a systematic review of the literature. World J Surg. 2015;39(5):1069-79.

30. Muto Y, Miyauchi H, Ohira G, Hayano K, Narushima K, Suzuki K, et al. Evaluation of the anastomotic blood flow with near-infrared ICG fluorescence angiography with intraoperative transanal endoscopy to predict anastomotic leakage after colorectal surgery. Chiba Medical J. 2018;94E:25-31.

31. Shen R, Zhang $Y$, Wang T. Indocyanine Green Fluorescence Angiography and the Incidence of Anastomotic Leak After Colorectal Resection for Colorectal Cancer: A Meta-analysis. Diseases of the Colon \& Rectum, 2018;61(10):1228-1234.

32. Kitagawa H, Namikawa T, Iwabu J, Fujisawa K, Uemura S, Tsuda S, et al., Assessment of the blood supply using the indocyanine green fluorescence method and postoperative endoscopic evaluation of anastomosis of the gastric tube during esophagectomy. Surg Endosc. 2018:32(4):1749-1754. Epub 2017 Sep 15.

33. Shimada Y, Okumura T, Nagata T, Sawada S, Matsui K, Hori R, et al. Usefulness of blood supply visualization by indocyanine green fluorescence for reconstruction during esophagectomy. Esophagus. 2011:8(4):259-266. 
34. Slooter MD, Eshuis WJ, Cuesta MA, Gisbertz SS, van Berge Henegouwen Ml. Fluorescent imaging using indocyanine green during esophagectomy to prevent surgical morbidity: a systematic review and meta-analysis. J Thorac Dis. 2019;11(Suppl 5):S755S765.

35. Degett TH, Andersen HS, Gögenur I. Indocyanine green fluorescence angiography for intraoperative assessment of gastrointestinal anastomotic perfusion: a systematic review of clinical trials. Langenbeck's archives of surgery, 2016;401(6):767-775.

36. Gosvig K, Steenstrup Jensen S, Qvist N, Nerup N, Agnus V, Diana $\mathrm{M}$ et al. Quantification of ICG fluorescence for the evaluation of intestinal perfusion: comparison between two software-based algorithms for quantification. Surg Endosc. 2020 Sep 23. Online ahead of print.

37. Jamil LH, Krause KR, Chengelis DL, Jury RP, Jackson CM, Cannon $\mathrm{ME}$, et al. Endoscopic management of early upper gastrointestinal hemorrhage following laparoscopic Roux-en-Y gastric bypass. Am J Gastroenterol. 2008;103(1):86-91. Epub 2007 Oct 17.

38. Zafar SN, Miller K, Felton J, Wise ES, Kligman M. Postoperative bleeding after laparoscopic Roux en $Y$ gastric bypass: predictors and consequences. Surg Endosc. 2019;33(1):272-280. Epub 2018 Sep 19.

39. Raiyani, T., et al., Bleeding from the Excluded Gastric Remnant after Roux-en-Y Gastric Bypass Controlled with Mesenteric Angiography: 639. Official journal of the American College of Gastroenterology I ACG, 2012. 107.

40. Puri V, Alagappan A, Rubin M, Merola S. Management of bleeding from gastric remnant after Roux-en-Y gastric bypass. Surg Obes
Relat Dis. 2012;8(1):e3-5. Epub 2010 Sep 16.

41. Saeki $Y$, Ide K, Kakizawa $H$, Ishikawa M, Tashiro $H$, Ohdan $H$ Controlling the bleeding of jejunal varices formed at the site of choledochojejunostomy: report of 2 cases and a review of the literature. Surg Today. 2013;43(5):550-5. Epub 2012 Jul 10.

42. Sasamoto A, Kamiya J, Nimura Y, Nagino M. Successful embolization therapy for bleeding from jejunal varices after choledochojejunostomy: report of a case. Surg Today. 2010; 40(8):788-91.

43. Waguri N, Azumi R, Sugimura K, Arao Y, Ikarashi S, Sakai N, et al., Jejunal varices after choledochojejunostomy treated with laparotomic transcatheter variceal embolization). Nihon Shokakibyo Gakkai Zasshi. 2016;113(11):1923-1931. Japanese

44. Ota S, Suzuki S, Mitsuoka H, Unno N, Inagawa S, Takehara Y, et al., Effect of a portal venous stent for gastrointestinal hemorrhage from jejunal varices caused by portal hypertension after pancreatoduodenectomy. J Hepatobiliary Pancreat Surg. 2005; 12(1):88-92.

45. Wakasugi M, Tsujie M, Goda S, Ohnishi K, Koga C, Tei M, et al., Laparotomy-assisted transcatheter variceal embolization for bleeding jejunal varices formed at the site of choledochojejunostomy: Report of a case and review of the literature. Int J Surg Case Rep. 2020;77:554-559.

46. Taniguchi $\mathrm{H}$, Moriguchi M, Amaike H, Fuji N, Murayama Y, Kosuga T. Hemorrhage from varices in hepaticojejunostomy in the fifth and tenth year after surgery for hepatic hilar bile duct cancer: a case report. Cases J. 2008;1(1):59. 